This document was prepared in conjunction with work accomplished under Contract No. DE-AC09-96SR18500 with the U. S. Department of Energy.

\title{
DISCLAIMER
}

This report was prepared as an account of work sponsored by an agency of the United States Government. Neither the United States Government nor any agency thereof, nor any of their employees, nor any of their contractors, subcontractors or their employees, makes any warranty, express or implied, or assumes any legal liability or responsibility for the accuracy, completeness, or any third party's use or the results of such use of any information, apparatus, product, or process disclosed, or represents that its use would not infringe privately owned rights. Reference herein to any specific commercial product, process, or service by trade name, trademark, manufacturer, or otherwise, does not necessarily constitute or imply its endorsement, recommendation, or favoring by the United States Government or any agency thereof or its contractors or subcontractors. The views and opinions of authors expressed herein do not necessarily state or reflect those of the United States Government or any agency thereof. 


\section{EVALUATION OF MINIATURIZED INFRARED SENSORS FOR PROCESS CONTROL OF THE PALLADIUM MEMBRANE REACTOR (U)}

R.J. Lascola

D.W. Howard

July, 2005 


\title{
DISCLAIMER
}

This report was prepared by Westinghouse Savannah River Company (WSRC) for the United States Department of Energy under Contract No. DE-AC09-96SR18500 and is an account of work performed under that contract. Neither the United States Department of Energy, nor WSRC, nor any of their employees makes any warranty, expressed or implied, or assumes any legal liability or responsibility for the accuracy, completeness, or usefulness, of any information, apparatus, or product or process disclosed herein or represents that its use will not infringe privately owned rights. Reference herein to any specific commercial product, process, or service by trademark, name, manufacturer or otherwise does not necessarily constitute or imply endorsement, recommendation, or favoring of same by WSRC or by the United States Government or any agency thereof. The views and opinions of the authors expressed herein do not necessarily state or reflect those of the United States Government or any agency thereof.

\author{
Printed in the United States of America \\ Prepared For \\ U.S. Department of Energy
}


Key Words: spectroscopy, gas analysis, carbon monoxide, water vapor, plug sensors

Retention: permanent

\section{EVALUATION OF MINIATURIZED INFRARED SENSORS FOR PROCESS CONTROL OF THE PALLADIUM MEMBRANE REACTOR (U)}

R.J. Lascola

D.W. Howard

July, 2005 


\section{REVIEWS AND APPROVALS}

\section{AUTHOR(S):}

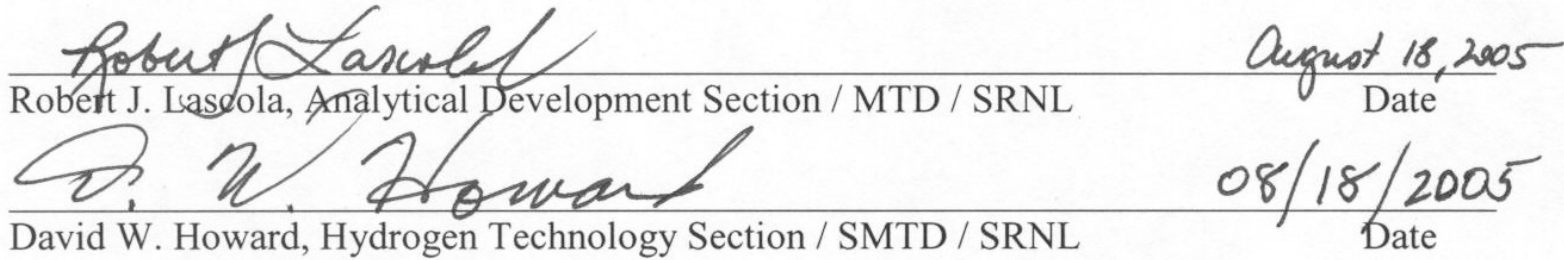

\section{TECHNICAL REVIEWERS:}

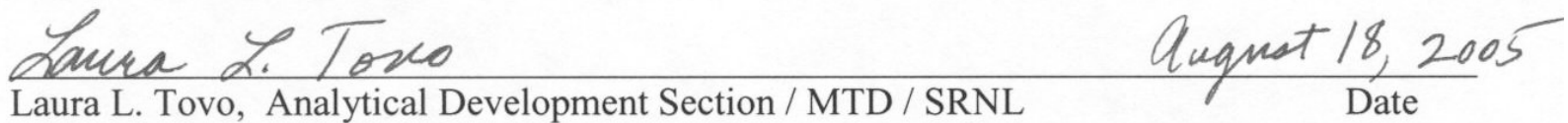

\section{APPROVERS}

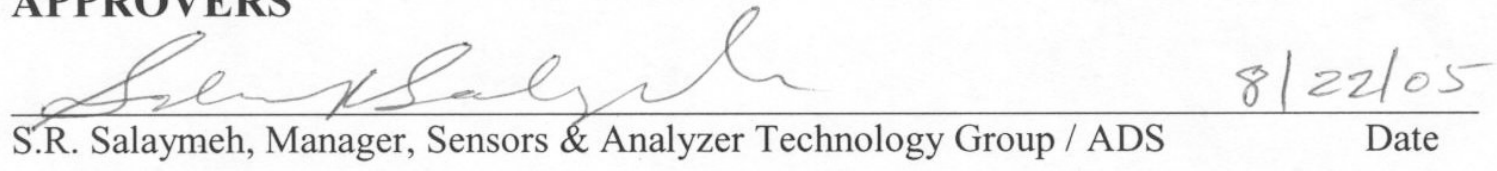

\section{DERIVATIVE CLASSIFICATION:}

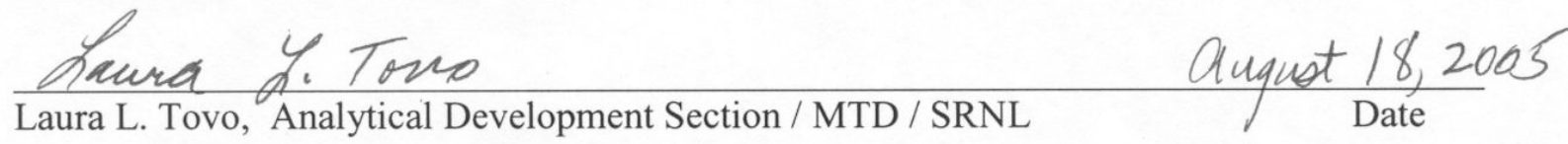




\section{EXECUTIVE SUMMARY}

We have tested the suitability of a miniaturized infrared sensor for measurements of $\mathrm{CO}$ and $\mathrm{H}_{2} \mathrm{O}$ in the inlet stream to the Palladium Membrane Reactor (PMR). We demonstrated that both analytes can be measured with absolute accuracies of $2-4 \%$ at the process inlet conditions of $120-140{ }^{\circ} \mathrm{C}$ and approximately 1 atm of each gas. This accuracy must be improved to 1-1.5\% for effective PMR process control. The use of a reference detector and independent temperature and pressure measurements to correct the raw signals will improve the accuracy to a level that will approach, if not meet, this goal. With appropriate bandpass filters, the infrared sensors may be used for other gas analysis applications. 


\section{TABLE OF CONTENTS}

EXECUTIVE SUMMARY iii

LIST OF FIGURES $\quad \mathrm{v}$

LIST OF TABLES $\quad$ V

LIST OF ACRONYMS vi

1.0 INTRODUCTION AND BACKGROUND 1

2.0 EXPERIMENTAL 2

2.1 Sensors 2

2.2 Gas Handling $\quad 4$

2.3 Calculations 5

3.0 RESULTS AND DISCUSSION

3.1 Experimental Results $\quad 5$

3.1.1 Sensor Stability 5

3.1.2 CO Sensor $\quad 7$

3.1.3 $\mathrm{H}_{2} \mathrm{O}$ Sensor $\quad 8$

3.1.4 Analyte Independence $\quad 8$

$\begin{array}{lr}3.1 .5 \text { Signal Averaging } & 10\end{array}$

3.2 Calculation Results 11

3.2.1 Methodology 12

3.2.2 Comparison to Experiment 12

3.2.3 Temperature Effects on Water Absorbances 14

3.2.4 Pressure Broadening 14

4.0 CONCLUSIONS 15

5.0 ACKNOWLEDGEMENTS 16

6.0 REFERENCES 16 


\section{LIST OF FIGURES}

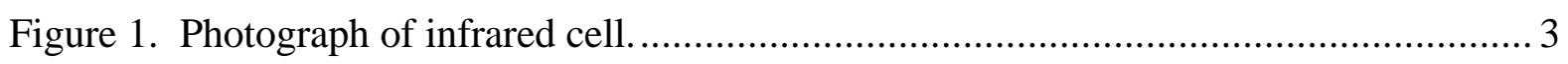

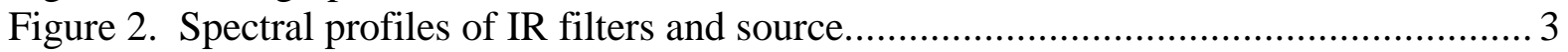

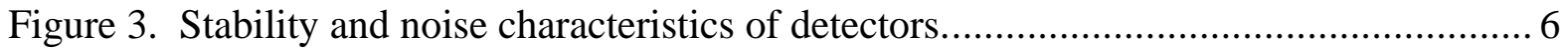

Figure 4. Relationship between pressure and absorbance for $\mathrm{CO}$........................................ 7

Figure 5. Relationship between pressure and absorbance for $\mathrm{H}_{2} \mathrm{O}$................................... 9

Figure 6. Pressure-dependent deviation from ideal gas law............................................... 10

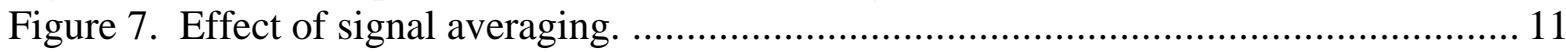

Figure 8. Relationship of pathlength and absorbance...................................................... 13

\section{LIST OF TABLES}

Table 1. Temperature dependence of $\mathrm{CO}$ absorbance ....................................................... 8

Table 2. Temperature dependence of $\mathrm{CO}$ and $\mathrm{H}_{2} \mathrm{O}$ absorbance...................................... 14

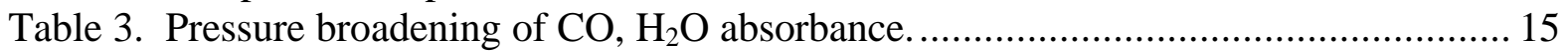




\section{LIST OF ACRONYMS}

au

GC

IR

LANL

MS

PMR

SRNL
Absorbance units

Gas chromatography

Infrared (absorption spectroscopy)

Los Alamos National Laboratory

Mass spectroscopy

Palladium Membrane Reactor

Savannah River National Laboratory 


\subsection{INTRODUCTION AND BACKGROUND}

The Palladium Membrane Reactor (PMR) is designed to recover hydrogen isotopes from water present as an impurity in tritium processing activities.[1,2,3] In the PMR, water and carbon monoxide $(\mathrm{CO})$ are catalytically reacted to form carbon dioxide $\left(\mathrm{CO}_{2}\right)$ and hydrogen at elevated temperatures and pressures (up to $425{ }^{\circ} \mathrm{C}$ and 2-3 atmospheres, respectively). The hydrogen is recovered by diffusion through a palladium $(\mathrm{Pd})$ membrane (driven by the partial pressure difference between the process pressure on one side and vacuum on the other side), which is selectively permeable to hydrogen. Most hydrogen will be present as protium. Only trace amounts of deuterium and tritium are expected.

The efficiency of the PMR reaction is governed by the $\mathrm{CO} /$ water concentration ratio. A slight excess of $\mathrm{CO}$ improves the kinetics of the reaction and promotes complete conversion of the water to elemental hydrogen; however, too much $\mathrm{CO}$ leads to fouling of the catalyst and/or Pd membrane with elemental carbon (soot), degrading the performance of the PMR. The recent failure of several Pd membrane tubes at Savannah River National Laboratory (SRNL) may be attributable in part to an excess of carbon, which may have been incorporated into the metallic structure, making it more susceptible to deformation and leaking.

The desired $\mathrm{CO} /$ water ratio is within a narrow range, 1.05-1.1. This suggests that the water and $\mathrm{CO}$ pressures must each be measured with absolute accuracies of $1-1.5 \%$ to obtain effective process control. ${ }^{*}$ The consequences of operation outside this band for an extended period of time highlight the need for accurate quantitation and control of the feed gases. The historical approach used to maintain the proper ratio is to measure and control the mass flow rates of each species individually before mixing them. Development work at Los Alamos National Laboratory (LANL) and SRNL has shown this approach to be not entirely satisfactory, as the mass flow measurement devices have not been sufficiently accurate to prevent process upsets. Therefore, flow control based on a more precise and reliable measurement technique is desirable.

Several techniques which have been widely applied to the general problem of process gas analysis include gas chromatography (GC), mass spectroscopy (MS), and infrared spectroscopy (IR).[4] However, GC and MS are not particularly suitable to PMR feed gas analysis. The feed gas is maintained at temperatures near $140{ }^{\circ} \mathrm{C}$ to keep water vaporized at high pressures. Process measurements with both GC and MS require capillaries to transport the sample to the instrument. Thus, extensive heat tracing is required to keep water from condensing in the lines, and the finite transport time of the gas makes these methods less responsive. Also, procurement and maintenance costs for these instruments are substantial.

Infrared spectroscopy is more amenable to the analysis problem, as it is readily introduced into the process environment and the target analytes are detectable at the process conditions. There are several IR techniques which could be considered. Fourier transform absorbance [5] and

\footnotetext{
${ }^{*}$ For example, a $1.25 \%$ uncertainty for a target $\mathrm{CO}$ pressure of $1.075 \mathrm{~atm}$ yields a range of $1.062-1.088 \mathrm{~atm}$. To maintain the $\mathrm{CO} /$ water ratio within the desired limits, the $\mathrm{H}_{2} \mathrm{O}$ pressure must be between $0.989-1.011 \mathrm{~atm}$. This range represents a $1.1 \%$ spread from the target pressure of $1.0 \mathrm{~atm}$.
} 
emission [6] spectroscopy, tunable diode laser spectroscopy [7], and cavity ring-down (timebased) spectroscopy [8] have all been successfully demonstrated for trace gases, and are commercially available. However, the capabilities of these methods are all far greater than what is required for the application. Instead, we have concentrated on finding a simple instrument that can be economically installed at several locations and is easy to operate.

Infrared plug sensors [9] meet this description. The plugs are small, rugged, and self-contained* They can be placed directly in the process stream and do not require fiber optics. They can be obtained in a variety of sampling configurations. Liquids and solids can be measured with attenuated total reflection on a single plug, while gases are analyzed by absorbance across the pipe diameter with separate source and detector plugs. Since the water and CO are the only stream constituents, and have absorptions that are spectrally distinct, an IR spectrometer is not required for the measurement. Instead, one may simply use two or three detectors whose wavelength responses are defined by bandpass filters.

This report describes characterization work done on one type of sensor, the Infraran model produced by Wilks Enterprises (Norwalk, CT). We studied the temperature and pressure dependence of the sensor response, potential interference effects occurring from different gas mixtures, short- and long-term accuracy and precision, the effect of different signal averaging options, and other environmental effects.

\subsection{EXPERIMENTAL}

\subsection{Sensors}

Figure 1 shows the gas cell and the sensor housing. The light source (labeled "A") is a pulsed diamond thin-film element, with an output approximated by a black body temperature of 800$850{ }^{\circ} \mathrm{C}$. There are two pyroelectric detectors mounted in a T08 can housing on the opposite side of the cell from the light source (labeled "B"). Glued in front of each detector is an infrared bandpass filter corresponding to either $\mathrm{CO}$ or $\mathrm{H}_{2} \mathrm{O}$ vibrational absorptions (near 4.7 and $2.7 \mu \mathrm{m}$, respectively). Figure 2 shows the blackbody emission and filter transmission spectra for these elements. No reference detector was provided. The source and detector interface the gas cell through cubic zirconia windows ( $2 \mathrm{~mm}$ thickness, $12.5 \mathrm{~mm}$ diameter) which are sealed with epoxy. The windows define a $3 \mathrm{~mm}$ absorption path length.

\footnotetext{
* Typically the plugs are 2" diameter. They have been tested to $150 \mathrm{psi}$ and $100{ }^{\circ} \mathrm{C}$. The light source and detector are mounted on the plug. Processing electronics can be on the plug or in a separate box.
} 


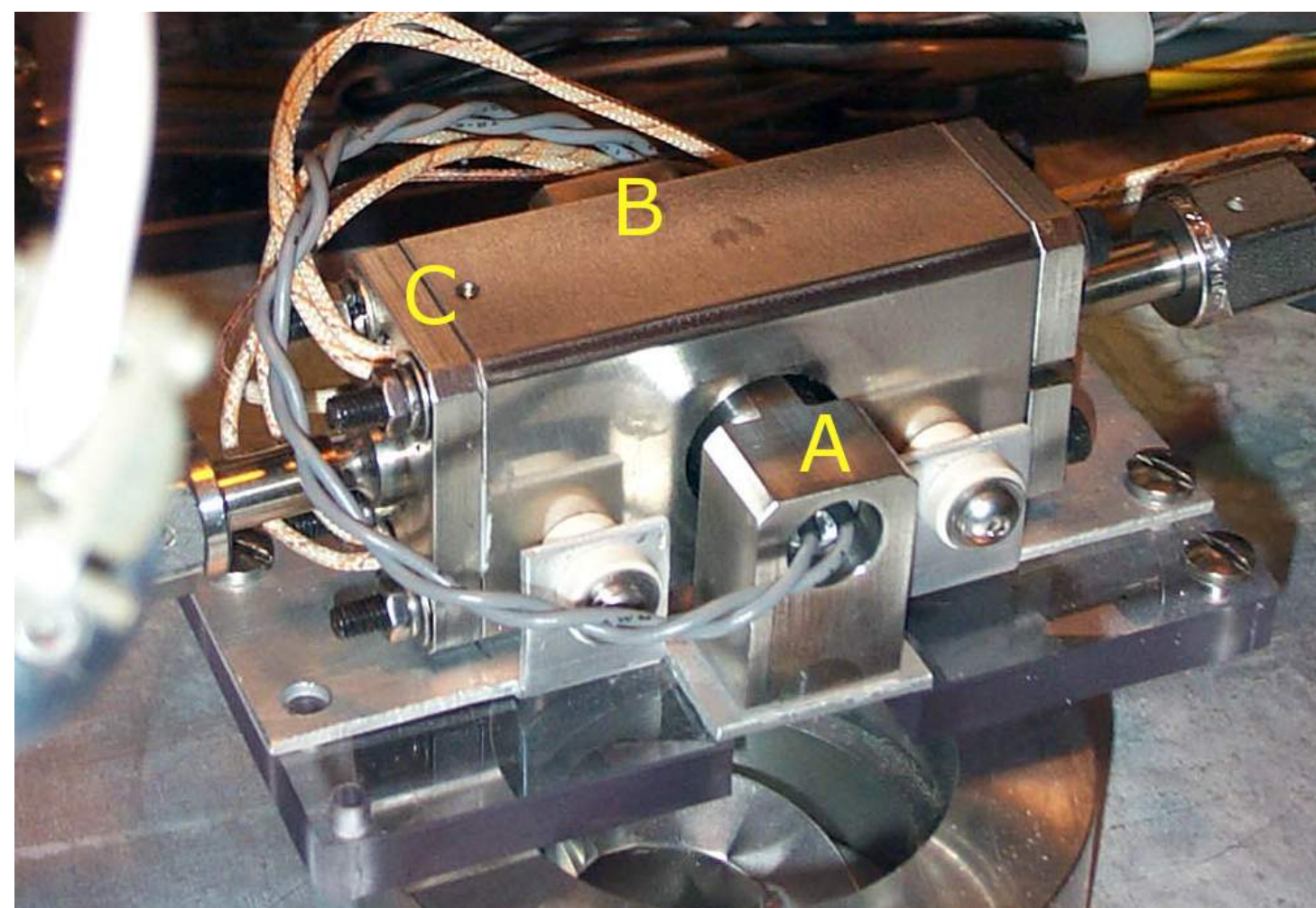

Figure 1. Photograph of infrared cell.

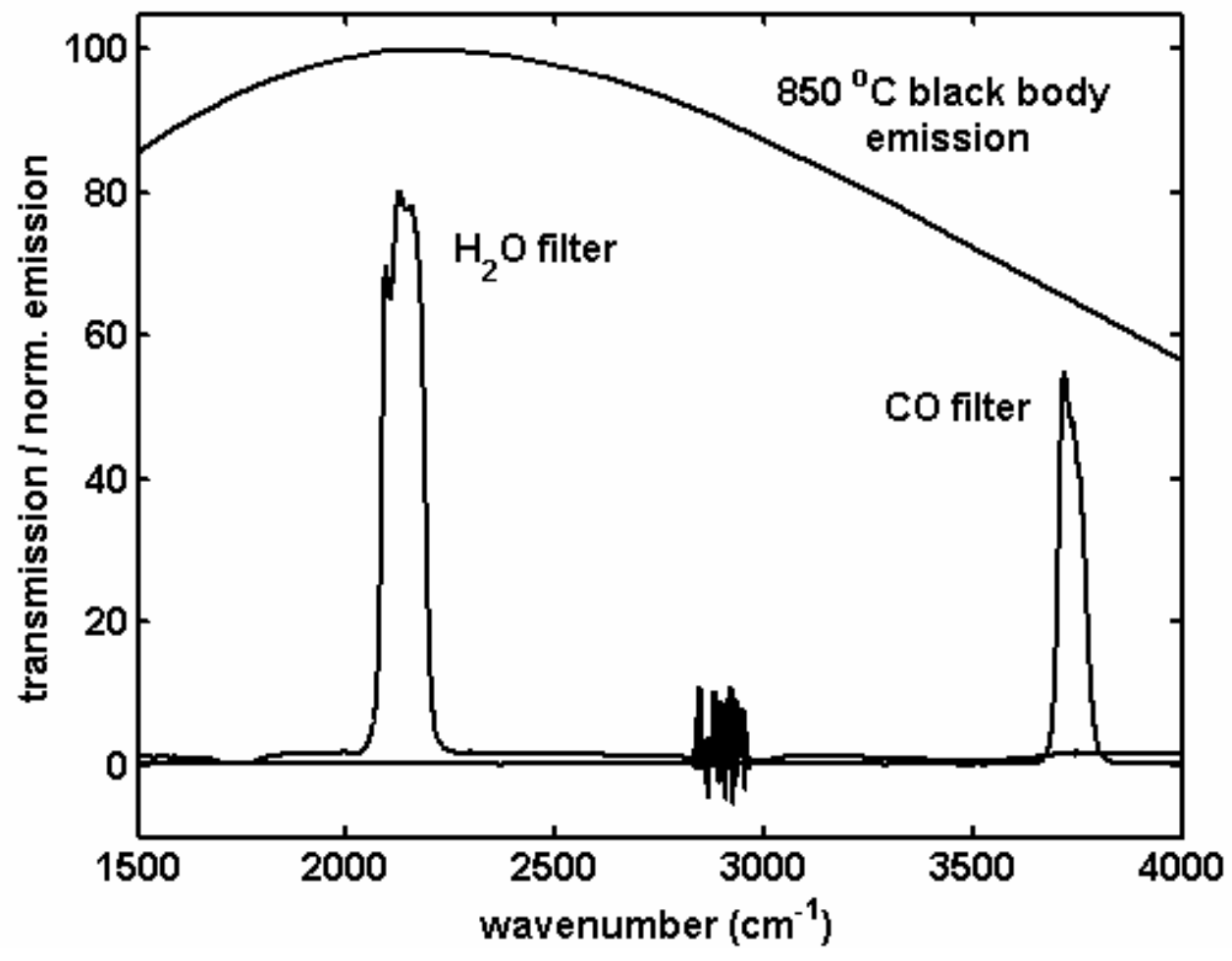

Figure 2. Spectral profiles of IR filters and source. 
The sample cell is constructed from stainless steel and is approximately $10 \mathrm{~cm}$ long and $2.5 \mathrm{~cm}$ wide. The internal cell volume has a rectangular cross-section $3 \mathrm{~mm}$ wide and $10 \mathrm{~mm}$ high. End caps with 1/4" female VCR fittings are attached to the cell with four pass-through bolts; seals are maintained with rubber gaskets. There are three holes in the sample cell body parallel to the internal cell. Two holes house cartridge heaters (labeled " $C$ " in Figure 1), and the third contains a thermocouple. These elements are connected to a temperature regulator.

Other supporting electronics include a control module that provides power to the source and detectors and monitors the detector output, and a processing unit that maintains the calibration and displays results. Output can also be logged onto a computer through a standard serial cable connection.

\subsection{Gas Handling}

The sample cell was spliced into a gas handling manifold which had previously been constructed for testing a PMR prototype. All lines were heat-traced by wrapping them in heating tape, foam insulation, and aluminum foil, and installing thermocouples to monitor the temperature.

Minimum temperatures of $120{ }^{\circ} \mathrm{C}$ were set in order to maintain water in the vapor phase at elevated pressures. Pressure was measured at several points in the manifold, including adjacent to the gas cell. CO was introduced from a standard gas cylinder (Scott). Steam was taken from a facility steam line. The entire gas system, including the sensor but not the display electronics, was contained in a large walk-in hood. Several $\mathrm{CO}$ and $\mathrm{CO}_{2}$ atmospheric sensors were employed to monitor leaks.

Sensor readings were obtained with gas pressures ranging from 14.5 - 40 psi. Readings were made on a static system. The pressure was varied by sequentially bleeding in or releasing a small amount of gas and allowing the system to equilibrate for 30-60 seconds. This time period was determined both by the signal averaging of the instrument (typically 30 seconds) and by gas transport issues associated with the narrow dimensions of the cell.

In the course of the work, two problems developed which precluded us from making all the desired measurements. First, it proved to be very difficult to maintain heat tracing so that water vapor did not condense somewhere in the line. Thus, water measurements were made on a dynamic system, where the instantaneously measured absorbances were compared with instantaneous pressures. Thus, the data obtained for those experiments did not have the same advantage of signal averaging as the $\mathrm{CO}$ data. Second, we intended to create $\mathrm{CO} / \mathrm{H}_{2} \mathrm{O}$ mixtures inside the sample cell by introducing a known pressure of one gas into the cell and then applying a greater pressure of the second gas. In testing this arrangement with $\mathrm{CO}$ and argon, we found that we could not remove residual amounts of the first gas added from lines leading to the cell. Thus, when the second gas was added, it swept in a certain amount of the first gas, and thus partial pressure of the first gas was not left constant. Due to time and equipment constraints, we were not able to install a vacuum pump to clear out those lines. We also could not heat trace a reservoir which would have been a more suitable gas mixing chamber. 


\subsection{Calculations}

Sensor response calculations were performed with Matlab, version 6.1 (Mathworks, Natick, MA). IR absorption spectra of $\mathrm{CO}$ and $\mathrm{H}_{2} \mathrm{O}$ were calculated from the 2000 HITRAN database using HITRAN-PC (ONTAR, N. Andover, MA). Bandpass filter spectra were provided by the vendor. Light source output was calculated assuming a $850^{\circ} \mathrm{C}$ black body source with a Webbased applet from Lawrence Berkeley Laboratory [10].

\subsection{RESULTS AND DISCUSSION}

\subsection{Experimental Results}

The sensor testing concentrated on those aspects associated with use in a process environment. Process temperature and pressure variations, external influences, and chemical changes must all be accommodated. A sensor could be insensitive to these factors, or its variations must be corrected by incorporating other measurements (typically pressure and temperature). Stability of the sensor, independent of process changes, must also be considered. A thorough understanding of these factors is required to assess both the viability of the sensor for the application and the resources needed to install and operate the sensor.

\subsubsection{Sensor Stability}

The Infraran sensors are designed to be operated at temperatures below $80-100{ }^{\circ} \mathrm{C}$. The limiting factor is expected to be the temperatures at which the on-board electronics can reliably operate. Since the gas temperature in the PMR system must be $120-140{ }^{\circ} \mathrm{C}$ to keep water in the vapor phase and improve the system efficiency, some accommodation must be made to protect the sensors while making the measurement. For the current system, this is done by using ceramic standoffs to maintain physical separation of the sensor mounting brackets and the gas cell. However, the separation between the sensor and the cell is only a few millimeters, and thus the sensors are likely to be near the upper end of their recommended operating temperature.

We therefore conducted a stability test to show that the sensors would operate effectively under these conditions. The cell was heated to $120{ }^{\circ} \mathrm{C}$, pressurized with $\operatorname{Ar}(\sim 39 \mathrm{psi})$, and sealed. The sensors were zeroed and the system was maintained at these conditions for over 30 hours. The measured absorbances (using a 30-second rolling average) for both $\mathrm{CO}$ and $\mathrm{H}_{2} \mathrm{O}$ channels are shown in Figure 3. With the exception of a relatively large spike near 1000 minutes, as seen in Figure $3 \mathrm{a}$, and a similar feature at the beginning of the study, the response of both sensors is stable (standard deviations of 0.0032 and 0.0046 absorbance units (au), respectively). 

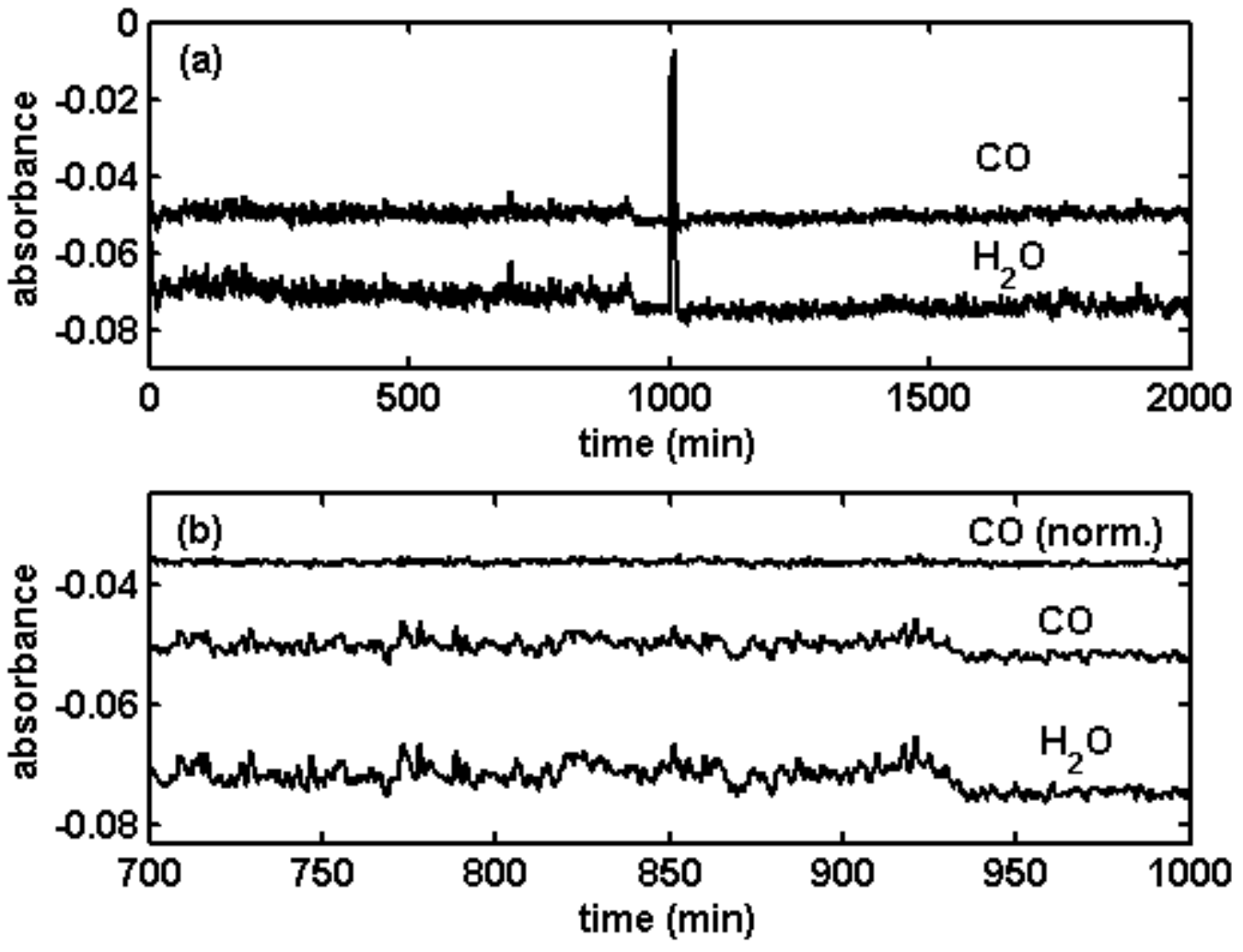

Figure 3. Stability and noise characteristics of detectors.

Several features of the figure merit further discussion. The sensors were located inside a walk-in vent room. After the sensors were zeroed, the vent room doors were closed, and both sensors recorded a 0.05-0.07 au offset that was maintained as long as the doors were closed. The sharp spikes back toward zero occurred when the doors were opened to look at the sensors. Further investigation revealed that when the doors were closed, there was a strong air flow through an opening at the top of the room directly onto the sensors, presumably cooling them. This behavior suggests that if the Infraran were to be used in a hot process environment, care would have to be taken to have the environmental conditions remain as consistent as possible. Sensor drift on this scale is much greater than the intrinsic sensor noise, and is significant on the scale of absorbance changes caused by $\mathrm{CO}$ and $\mathrm{H}_{2} \mathrm{O}$ with this gas cell.

An expanded view of the sensor response (Figure $3 \mathrm{~b}$ ) shows that the $\mathrm{CO}$ and $\mathrm{H}_{2} \mathrm{O}$ noise is highly correlated $(\rho=0.79)$, supporting the suggestion that environmental variations in this test are greater than intrinsic sensor variations. The latter can be estimated by treating the $\mathrm{H}_{2} \mathrm{O}$ channels a reference and dividing it into the $\mathrm{CO}$ channel response to normalize the latter. After multiplying by the $\mathrm{H}_{2} \mathrm{O}$ channel average (about $0.07 \mathrm{au}$ ), one obtains the top trace in Figure $3 \mathrm{~b}$, which has less variation than the individual curves. The standard deviation of the normalized set is $0.00091 \mathrm{au}$, which is 3.5 times better than the raw signal. The improved performance strongly suggests that a reference channel should be used in future configurations. 


\subsubsection{CO Sensor}

Absorbance values as a function of system pressure were obtained for $100 \% \mathrm{CO}$ at temperatures ranging from $23-140{ }^{\circ} \mathrm{C}$. The absorbance increased monotonically with pressure increase, and the results are reproducible across several pressure cycles. Typical data $\left(120{ }^{\circ} \mathrm{C}\right)$ showing the dependence of pressure (measured in absolute psi) on absorbance, along with a best fit line, are shown in Figure 4. Although the absorbance was the dependent variable during data collection, it is shown as the independent variable to be more representative of how the sensor would be used in practice.

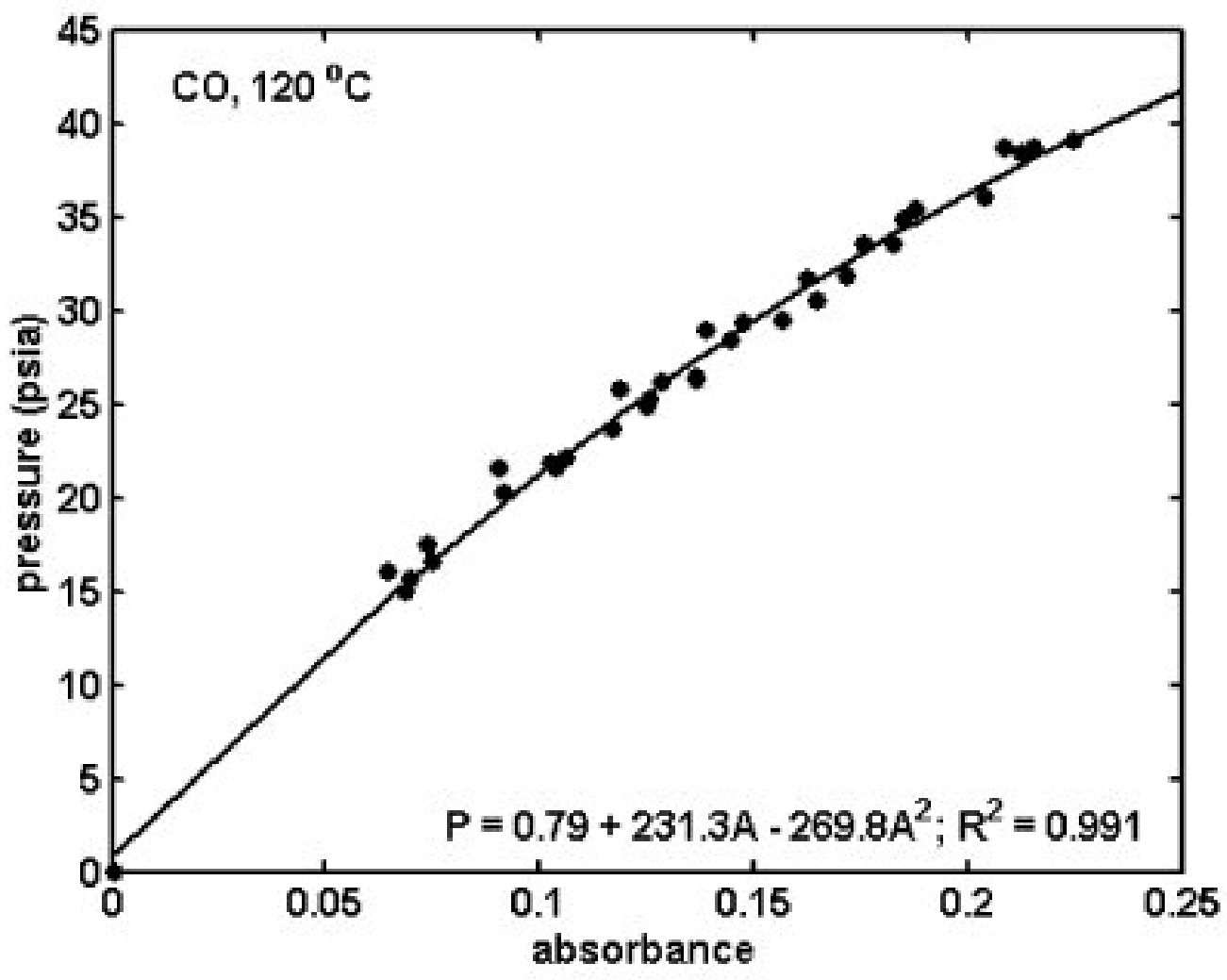

Figure 4. Relationship between pressure and absorbance for $\mathrm{CO}$.

Table 1 shows the quadratic fit parameters for each temperature $\left(P(p s i a)=a_{0}+a_{1} A+a_{2} A^{2}\right)$. Several points are apparent. The intercepts $\left(\mathrm{a}_{0}\right)$ are zero or nearly zero for all temperatures. The linear coefficients $\left(a_{1}\right)$ generally increase with temperature. This may be expected if the increasing temperatures result in the population of higher rotational levels, which would lead to more absorption lines appearing within the filter bandpass (at the expense of lines outside the bandpass). Thermal expansion of the cell may also account for a small portion of the increase. The quadratic term $\left(a_{2}\right)$ is statistically significant at all temperatures, which represents a deviation from the linear behavior predicted from Beer's Law. ${ }^{*}$ However, nonlinearity may be

\footnotetext{
${ }^{*} \mathrm{~A}=\varepsilon b \mathrm{c}$, where $\varepsilon$ is the absorptivity of the molecular transition, $\mathrm{b}$ is the measurement pathlength, and $\mathrm{c}$ is the concentration.
} 
expected under certain conditions which are met in these measurements. This topic will be further examined during the discussion of sensor response calculations, below.

Table 1. Temperature dependence of $\mathrm{CO}$ absorbance.

\begin{tabular}{|c|c|c|c|c|c|}
\hline $\mathbf{T}\left({ }^{\mathbf{0}} \mathbf{C}\right)$ & $\mathbf{a}_{\mathbf{0}}(\mathbf{1 \sigma})$ & $\mathbf{a}_{\mathbf{1}}(\mathbf{1 \sigma})$ & $\mathbf{a}_{\mathbf{2}}(\mathbf{1 \sigma})$ & $\mathbf{R}^{\mathbf{2}}$ & Std err (\%) \\
\hline 23 & $0.88(0.76)$ & $129(7)$ & $-49(17)$ & 0.9976 & 1.6 \\
\hline 50 & $0.03(0.55)$ & $160(6)$ & $-105(18)$ & 0.9894 & 2.6 \\
\hline 85 & $2.3(0.7)$ & $188(10)$ & $-154(34)$ & 0.979 & 3.3 \\
\hline 120 & $0.8(0.7)$ & $231(11)$ & $-270(42)$ & 0.991 & 3.3 \\
\hline 140 & $4.7(0.3)$ & $220(5)$ & $-181(22)$ & 0.9982 & 1.4 \\
\hline
\end{tabular}

Note also that each fit replicates the measurements within 2-3\%. This accuracy is consistent with the control requirements described above. However, these tests were conducted under controlled conditions and were of a relatively short duration. Greater uncertainties, and the need for compensatory measurements, would be expected in less controlled conditions.

\subsection{3 $\mathrm{H}_{2} \mathrm{O}$ Sensor}

For reasons described in the experimental section, it was not possible to get time averaged absorbance data for a fixed water vapor pressure in the cell. Consequently, the uncertainties associated with this analysis are greater than for the $\mathrm{CO}$ analysis. There is no reason otherwise that the analysis of water vapor should be any less accurate than for $\mathrm{CO}$; therefore, the results reported here should not be considered a true measure of the potential system performance. Data was only acquired at $140{ }^{\circ} \mathrm{C}$, so no temperature dependence of the coefficients was obtained. The $140^{\circ} \mathrm{C}$ data is presented in Figure 5. The sensor response to water is similar to the CO response, particularly with the statistically significant negative quadratic dependence on absorbance.

\subsubsection{Analyte Independence}

Because both the water and $\mathrm{CO}$ measurements are univariate (relying on the signal of a single detector), accurate measurement of each requires that the measurements be independent. Independence must not only be intrinsic, e.g. there are no overlapping absorption peaks, but also extrinsic, e.g. water and $\mathrm{CO}$ do not interact so as to appreciably change the absorption of either.

Intrinsic independence is expected based on calculations using the HITRAN atmospheric database; there are no CO absorptions predicted in the $3680-3800 \mathrm{~cm}^{-1}$ range of the $\mathrm{H}_{2} \mathrm{O}$ filter, nor are there $\mathrm{H}_{2} \mathrm{O}$ absorptions in the $2060-2210 \mathrm{~cm}^{-1}$ range of the $\mathrm{CO}$ filter. Measurements of pure $\mathrm{CO}$ and pure $\mathrm{H}_{2} \mathrm{O}$ vapor confirm this result. The correlation coefficient $(\rho)$ for the $\mathrm{CO}$ sensor in the presence of water is 0.12 . The correlation coefficient for $\mathrm{H}_{2} \mathrm{O}$ in the presence of $\mathrm{CO}$ is somewhat larger, 0.29 , but this value may reflect environmental effects, as discussed above. These results confirm that the detectors are intrinsically independent. 


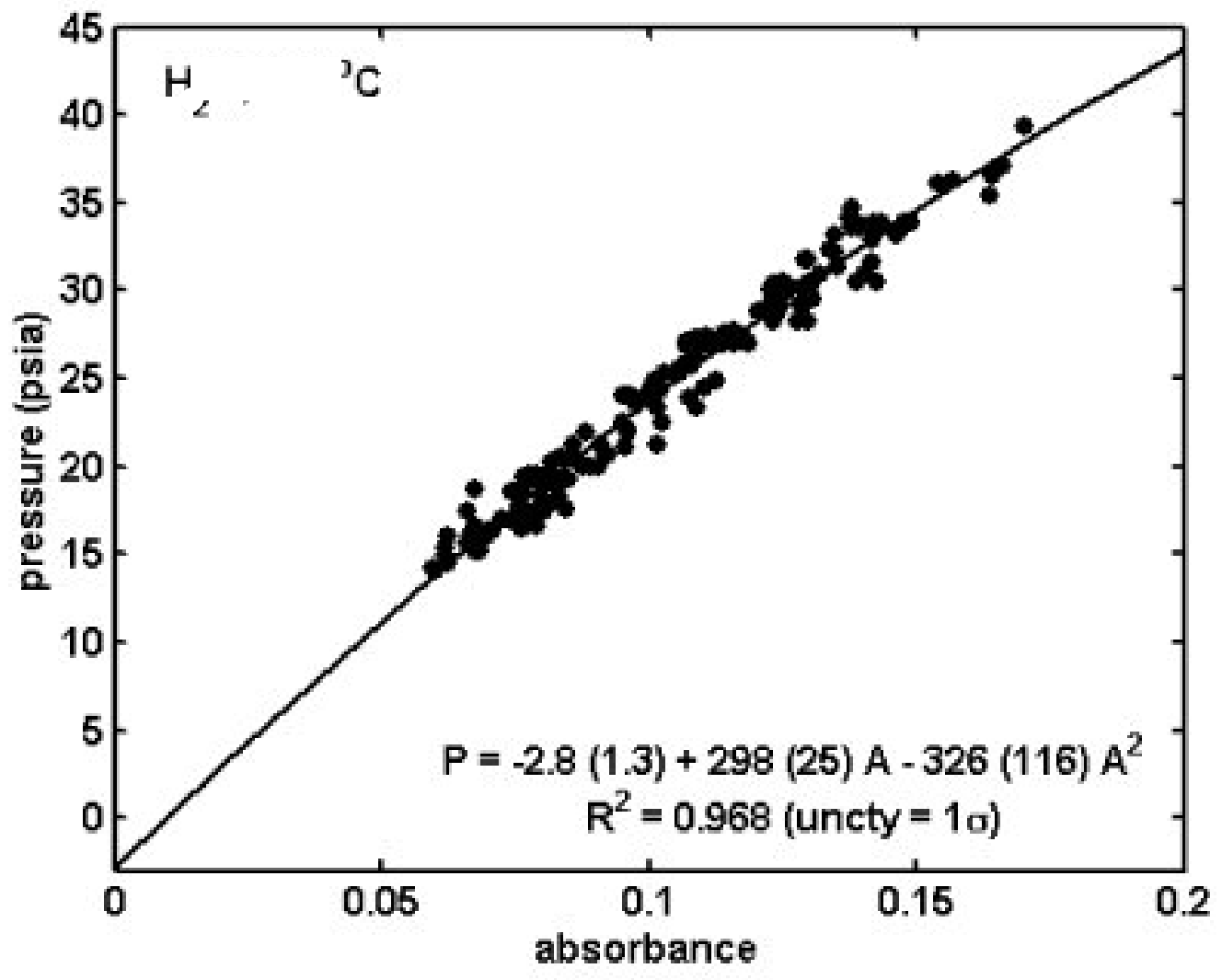

Figure 5. Relationship between pressure and absorbance for $\mathrm{H}_{2} \mathrm{O}$.

Extrinsic interactions may be considerable given the strong hydrogen-bonding potential of $\mathrm{H}_{2} \mathrm{O}$ and $\mathrm{CO}$. The effect of these interactions on gas number density, which in turn affects absorption, can be estimated from the van der Waals gas equation [11]:

$$
\begin{gathered}
\left(\mathrm{P}+\mathrm{a} / v^{2}\right)(v-\mathrm{b})=\mathrm{RT} \\
v=\mathrm{V} / \mathrm{n}
\end{gathered}
$$

Here, $\mathrm{P}, \mathrm{V}$, and $\mathrm{T}$ are the system pressure, volume, and temperature, $\mathrm{R}$ is the ideal gas constant, $\mathrm{n}$ is the total moles of gas, and $\mathrm{a}$ and $\mathrm{b}$ are molecule-specific interaction constants. The molar gas density is represented by $v^{-1}$. For a mixture, the effective interaction constants can be determined from the constants for the components:

$$
\begin{aligned}
& \mathrm{a}_{\text {eff }}=\sum_{i} \sum_{i} f_{i} f_{i}\left(a_{i} a_{i}\right)^{1 / 2} \\
& \mathrm{~b}_{\text {eff }}=\sum_{i} \sum_{j} f_{i} f_{j}\left(b_{i} b_{j}\right)^{1 / 2}
\end{aligned}
$$


where each summation is over all components, and $f_{i}$ is the molar fraction of the $i^{\text {th }}$ component.

The effect of water on CO number density, and vice versa, can be seen in Figure 6. Here, the partial pressure of the labeled component is fixed at 14.7 psia (1 atm), while the partial pressure of the other component varies from 7.35 to 22.35 psia. The effect is plotted as a deviation from the ideal gas law. This calculation also takes into account self-interactions (e.g. CO-CO or $\mathrm{H}_{2} \mathrm{O}-$ $\mathrm{H}_{2} \mathrm{O}$ ). It may be seen that near the typical PMR operating conditions of 2 atm total pressure, the number density correction for each gas is approximately $0.5 \%$. The correction changes by a few tenths of a percent with expected temperature and pressure variations within the PMR process.

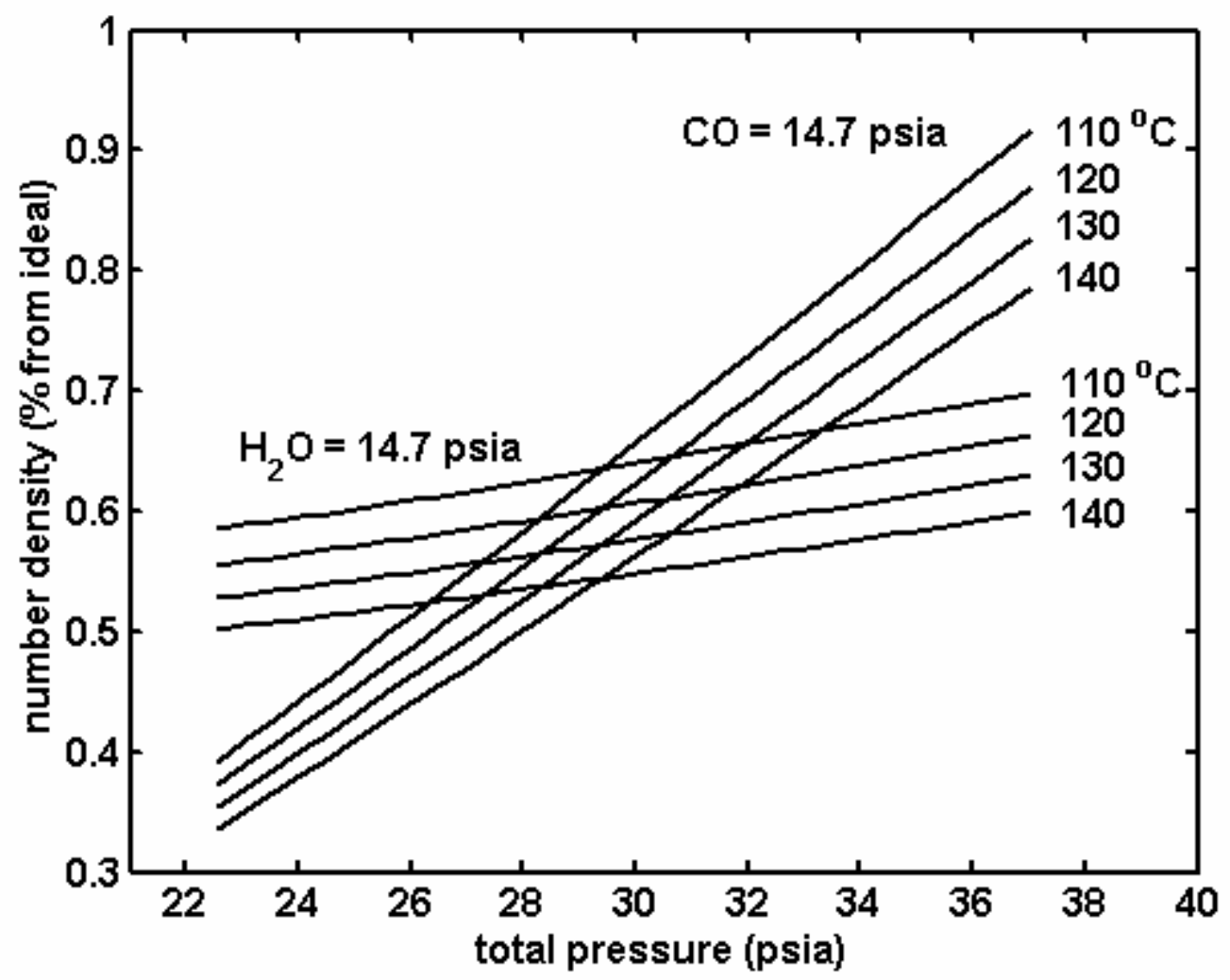

Figure 6. Pressure-dependent deviation from ideal gas law.

This change is significant compared to the desired 1-1.5\% uncertainty of the measurement. However, a correction based on a temperature measurement can be made readily. As both intrinsic and extrinsic interactions are negligible or correctible, we can conclude that the water and $\mathrm{CO}$ signals are adequately independent.

\subsubsection{Signal Averaging}

The sensor manufacturer supplied the control system with a fixed rolling average of 30 seconds applied to the displayed gas concentrations. We wished to determine if a shorter time constant would provide adequate noise reduction while allowing for a faster system response. The data stream includes instantaneous intensity readings, which can be converted to absorbances. A 
section of this data for a $\mathrm{CO}$ cycling experiment is shown in Figure 7. In addition to the raw data, data averaged over 7.5, 15, and 30 seconds is shown. Averaged data is offset for clarity.

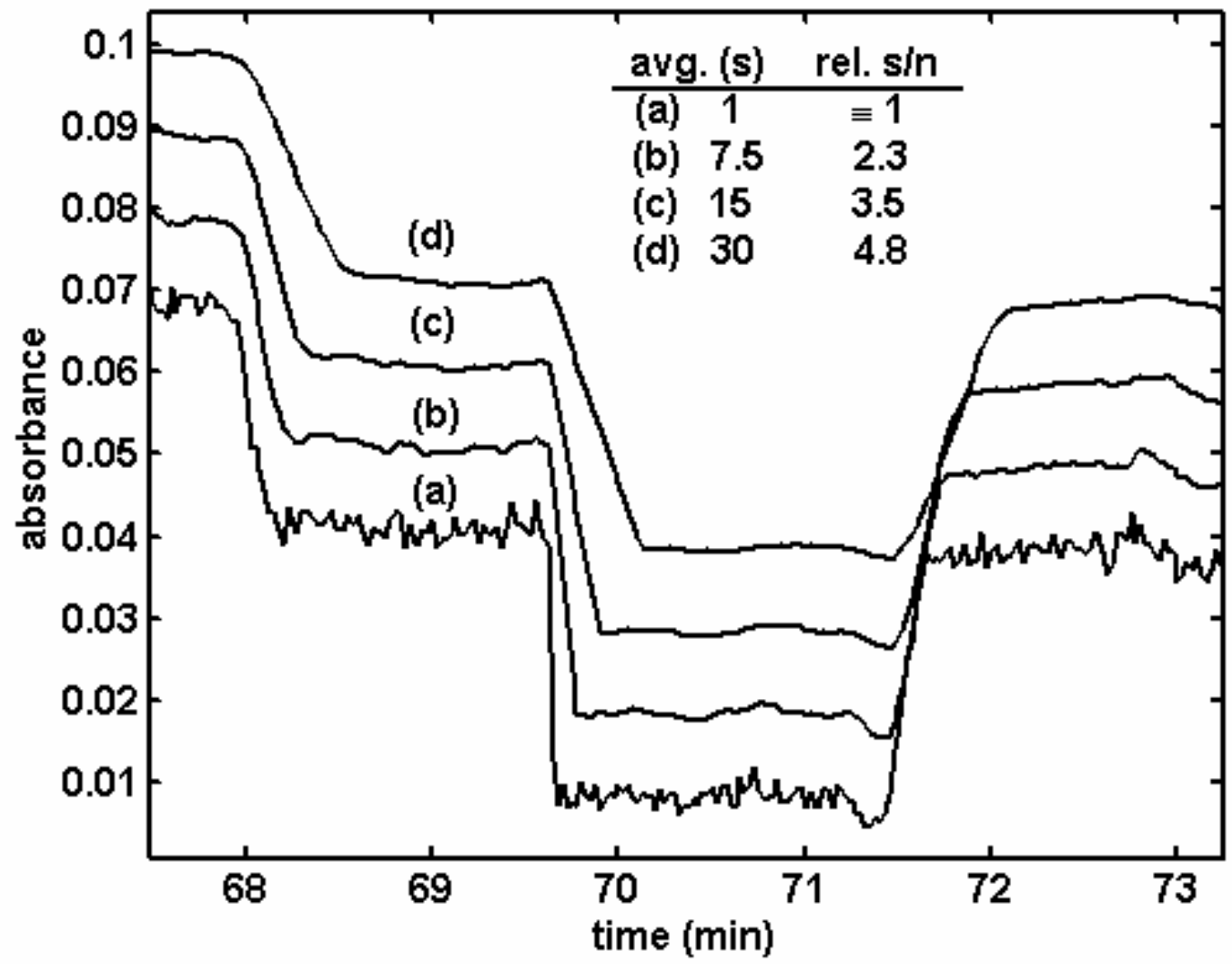

Figure 7. Effect of signal averaging.

Noise reduction, as measured by the standard deviation of the signal with constant $\mathrm{CO}$, improves at a rate slightly less than the square root of the relative time constant. The effect of the time constant on the response to a (near-)instantaneous change in gas concentration can also be seen.

The fit results of Table 1 suggest that the longer signal averaging should be maintained. However, as environmental variations have been shown to play an important role in sensor response, the use of a dedicated reference detector may allow for a shorter averaging time.

\subsection{Calculation Results}

We supplemented the experimental measurements with calculations simulating sensor response under a variety of conditions. In some cases, this approach was required because we could not successfully prepare gas mixtures with water vapor. In other cases, the sensor/flow cell configuration (e.g. pathlength) could not be changed. The calculations expand our understanding of sensor properties. They can also serve as a template for predicting the viability of the sensors for applications with different operating conditions and/or analytes. 


\subsubsection{Methodology}

The signal generated by each detector can be calculated by convolving the effects of each optical element on the spectrum of the light propagated through the system. The four primary elements are the source, sample, filters, and detector:

$$
S(\omega)=I_{\text {lamp }}(\omega) \times T_{\text {sample }}(\omega) \times T_{\text {filter }}(\omega) \times Q_{\text {detector }}(\omega)
$$

where $S$ represents detector signal, $I$ light intensity, $T$ transmission, and $Q$ quantum efficiency, all of which are dependent on the light frequency, $\omega$.

Several assumptions are made with the calculations. Detector efficiency is assumed constant over the frequency range defined by an individual filter $\left(Q_{\text {detector }}=1\right)$. Likewise, any reflections at the interfaces in the optical path are assumed not to have a frequency dependence.

Calculations are made for a discrete array of frequencies defined by the highest-resolution data set, which in this case is $T_{\text {sample. }}$ The other factors, $I_{\text {lamp }}$ and $T_{\text {filter }}$, are interpolated to the higher resolution with a spline fit. Calculations were made with different resolutions for $T_{\text {sample, }}$, and consistent results were obtained for resolutions smaller than or equal to $0.01 \mathrm{~cm}^{-1}$. Because the finer resolutions require a larger data set, the maximum spacing was used for subsequent calculations.

$S$ is summed over all frequencies to determine a total signal. Absorbance is calculated from the ratio of the signals for a "zero" gas and the analyte:

$$
\mathrm{A}=-\log _{10}\left(S_{\text {analyte }} / S_{\text {zero }}\right)
$$

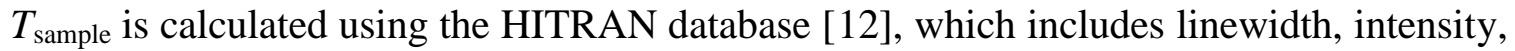
pressure coefficients, and other parameters for all observed infrared, visible, and ultraviolet spectral lines for a number of atmospherically important small molecules. The calculation of gas transmission profiles requires the control of a large number of parameters. All gas concentrations apart from $\mathrm{H}_{2} \mathrm{O}$ and $\mathrm{CO}$ were set to zero. Temperatures and partial and total pressures were specified. A horizontal beam path was selected to remove any altitude effects on the calculation. The smallest available pathlength $(1 \mathrm{~cm})$ was chosen. As this value is larger than the gas cell pathlength $(0.3 \mathrm{~cm})$, a correction to the results was made (see below).

\subsubsection{Comparison to Experiment}

The ability of a calculation to replicate experimental results gives a measure of confidence for subsequent calculations. There are two experiments in this study for which a comparison can be made - measurement of $\mathrm{CO}$ absorbances at a given temperature, and the replication of temperature-dependent absorption trends for $\mathrm{CO}$.

The comparisons require a correction of the long pathlength used in the calculations. Beer's Law, which describes a linear relationship between pathlength and absorbance, does not apply when absorbances are saturated (e.g. all of the light at a certain frequency is absorbed by the 
sample). In these cases, the absorbance will be less than predicted from a linear extrapolation from shorter pathlengths. This is seen in Figure 8, which shows the calculated absorbance for different pathlengths and $\mathrm{CO}$ pressures. There is a readily apparent quadratic component to the dependence that is more pronounced for higher pressures. This feature is consistent with more saturated transitions within the filter transmission envelope at the higher pressures. It is also interesting to note the onset of nonlinearities at relatively low absorbances. This occurs because the absorbance is an integrated quantity that includes both saturated transitions and regions with no absorbance. Therefore, the average absorbance for the region is less than what is normally observed when a transition becomes saturated.

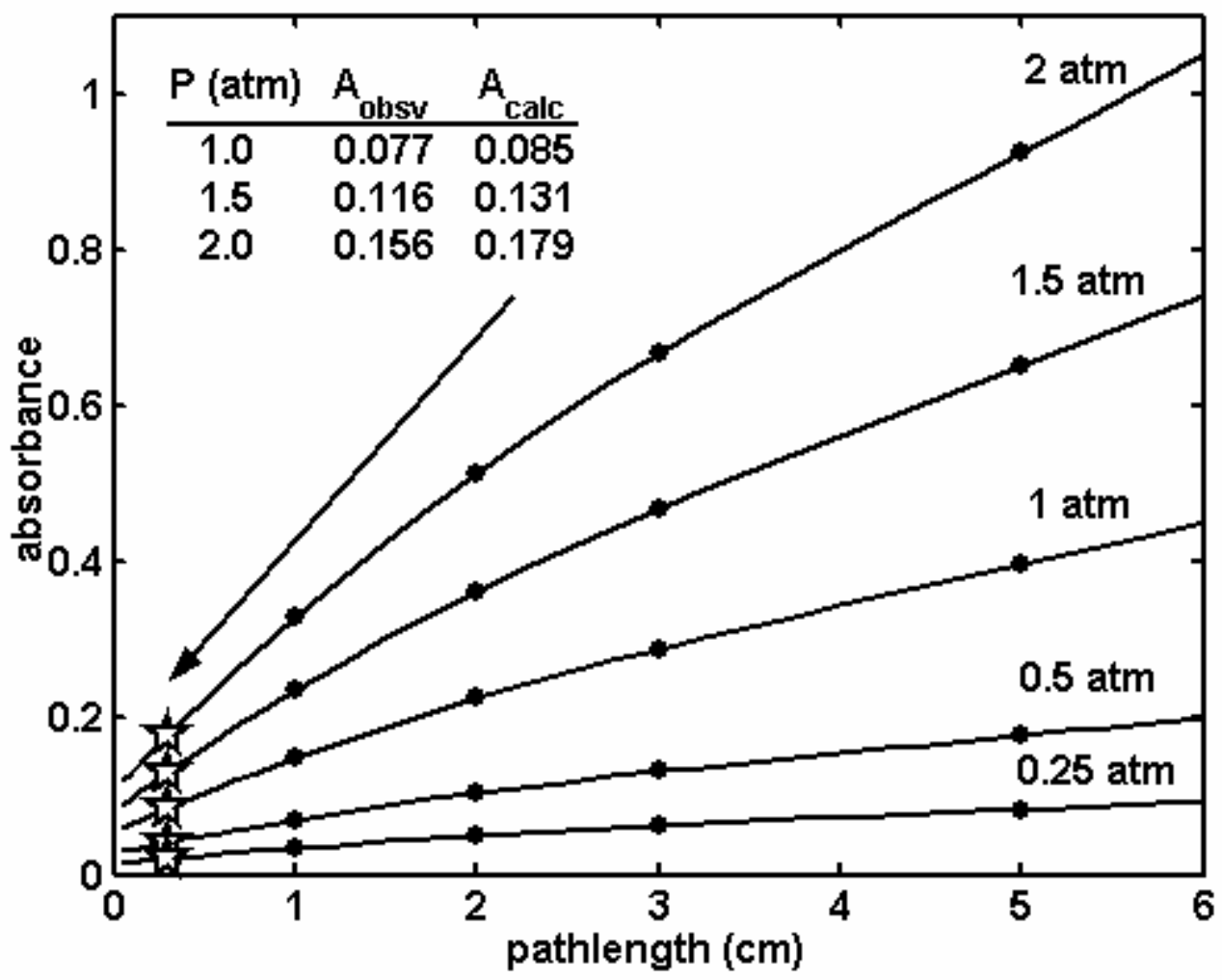

Figure 8. Relationship of pathlength and absorbance.

There are hundreds of narrow absorbance lineshapes within the filter transmission envelope. The number of saturated transitions increases with increasing pathlength, and is non-zero at the shortest available pathlength for the calculation. It is reasonable to assume that at shorter pathlengths, the number of saturated transitions will decrease proportionally. Thus, we can estimate absorbances for the cell pathlength by extrapolating a spline fit to the calculated absorbances. The predicted absorbances for the cell are shown by the stars in Figure 8 , and the values are compared to experimental results in the inset. There is good agreement between the two values, considering the inherent assumptions. The agreement indicates that the calculations are representative of experimental results. 
A similar level of agreement between experiment and calculation is seen for the temperature dependence of absorbance, as shown in Table 2. Here, the $\mathrm{CO}$ or $\mathrm{H}_{2} \mathrm{O}$ pressure was fixed at 14.7 psia (1 atm). Absorbances are calculated for $1 \mathrm{~cm}$ and corrected to $0.3 \mathrm{~cm}$ by dividing by 1.75 , the ratio determined from Figure 8.

Table 2. Temperature dependence of $\mathrm{CO}$ and $\mathrm{H}_{2} \mathrm{O}$ absorbance.

\begin{tabular}{|c|c|c|c|c|c|}
\hline Temp (K) & $\mathbf{2 9 8}$ & $\mathbf{3 2 3}$ & $\mathbf{3 5 8}$ & $\mathbf{3 9 3}$ & $\mathbf{4 1 3}$ \\
\hline $\mathbf{A}_{\text {CO }}$ (obsv.) & 0.115 & 0.100 & 0.072 & 0.071 & 0.063 \\
\hline $\mathbf{A}_{\text {CO }}$ (calc.) & 0.103 & 0.098 & 0.093 & 0.088 & 0.085 \\
\hline $\mathbf{A}_{\text {H2O }}$ (calc.) & 0.063 & 0.062 & 0.061 & 0.060 & 0.059 \\
\hline $\mathbf{A}_{\text {CO }} / \mathbf{A}_{\mathbf{H} 2 O}$ & 1.63 & 1.58 & 1.52 & 1.46 & 1.43 \\
\hline
\end{tabular}

The observed and calculated $\mathrm{CO}$ absorbances both decrease as temperature increases (the temperature dependence is less marked for the calculation). One contributing factor is the decrease in $\mathrm{CO}$ number density caused by fixing both pressure and volume while changing the temperature. Another is a temperature-induced population shift to higher rotational ground states that favors transitions that are outside the filter envelope.

The ability of the calculations to replicate $\mathrm{CO}$ absorption measurements and temperaturedependent trends gives a measure of confidence that similar calculations will give good results.

\subsubsection{Temperature Effects on Water Absorbances}

Table 2 also shows the calculated effect of temperature on water measurements. As with $\mathrm{CO}$, there is a decrease in the absorbance, though the decrease is much smaller (6\% versus $17 \%$ between 298 and $413 \mathrm{~K}$ ). This is due to the rotational energy level distribution for water. For this symmetric top molecule, transitions from different rotational ground states are interspersed instead of being in a regular progression, as is the case for a diatomic molecule. Thus, population transfer to higher energy states does not change the line overlap with the filter envelope as much as occurs for a diatomic.

Note that the ratio of the $\mathrm{CO}$ and $\mathrm{H}_{2} \mathrm{O}$ absorbances changes by $2 \%$ in the expected PMR process range of $120-140{ }^{\circ} \mathrm{C}$. This deviation can be readily corrected if the temperature is independently measured.

\subsubsection{Pressure Broadening}

Molecular absorption profiles are sensitive to pressure broadening effects. [13] Specifically, linewidths will increase due to a decrease in excited state lifetimes and an increase in energy level perturbations. This effect is manifested through an intrinsic change in the analyte (the absorptivity) and so differs from the extrinsic changes described above. Note that for a strongly saturated transition, the peak will remain saturated despite the transfer of absorption strength to the wings of the transition. Since there are many such transitions within the filter envelope, pressure broadening is expected to increase the overall absorbance at a given analyte partial pressure. 
Pressure broadening effects for $\mathrm{CO}$ and $\mathrm{H}_{2} \mathrm{O}$ were calculated for expected PMR process conditions. The target gas was assumed to have a partial pressure of $14.7 \mathrm{psia}(1 \mathrm{~atm})$, with air providing the balance of the total pressure. ${ }^{*}$ Total pressure ranged from 26.5 to 32.3 psia (1.8 $2.2 \mathrm{~atm})$. The temperature was fixed at $140{ }^{\circ} \mathrm{C}$. The pathlength was $0.01 \mathrm{~m}$. Results of the calculation are shown in Table 3.

Table 3. Pressure broadening of $\mathrm{CO}, \mathrm{H}_{2} \mathrm{O}$ absorbance.

\begin{tabular}{|c|c|c|c|c|c|}
\hline $\mathbf{P}_{\text {total }}(\mathbf{a t m})$ & $\mathbf{1 . 8}$ & $\mathbf{1 . 9}$ & $\mathbf{2 . 0}$ & $\mathbf{2 . 1}$ & $\mathbf{2 . 2}$ \\
\hline $\mathbf{A}_{\text {CO }(\mathbf{0 . 2 5} \text { atm })}$ & 0.198 & 0.203 & 0.209 & 0.214 & 0.219 \\
\hline $\mathbf{A}_{\text {H2O (0.25 atm) }}$ & 0.126 & 0.128 & 0.130 & 0.132 & 0.134 \\
\hline
\end{tabular}

The expected absorbance increases are observed for both $\mathrm{CO}$ and $\mathrm{H}_{2} \mathrm{O}$, although the increase is proportionally greater for $\mathrm{CO}(11 \%)$ than $\mathrm{H}_{2} \mathrm{O}(6 \%)$. This may be due to a higher density of saturated transitions within the filter envelope for $\mathrm{CO}$. Different air broadening parameters for $\mathrm{CO}$ and $\mathrm{H}_{2} \mathrm{O}$ [12] may also have a small effect. The increases are sufficiently large to merit a post-measurement correction to meet PMR control requirements.

\subsection{CONCLUSIONS}

The primary goal of this work is to determine the suitability of the Infraran sensor for use in the Palladium Membrane Reactor. This application presents a challenge for the sensor, since the process temperature exceeds its designed operating range. We have demonstrated that large baseline offsets, comparable to the sensor response to the analyte, are obtained if cool air is blown across the sensor. We have also shown that there is a strong environmental component to the noise. However, the current arrangement does not utilize a reference detector. The strong correlation between the $\mathrm{CO}$ and $\mathrm{H}_{2} \mathrm{O}$ sensor responses to environmental changes indicate that a reference detector can greatly reduce the environmental sensitivity. In fact, incorporation of a reference detector is essential for the sensor to work in this application.

We have also shown that the two sensor responses are adequately independent. Still, there are several small corrections which must to be made to the sensor response to accommodate chemical and physical effects. Interactions between the two analytes will alter the relationship between number density and pressure. Temperature and pressure broadening will alter the relationship between absorbance and number density. The individual effects are small - on the order of a few percent or less - but cumulatively significant. Still, corrections may be made if temperature and total pressure are independently measured and incorporated into a post-analysis routine. Such corrections are easily programmed and automated and do not represent a significant burden for installation.

\footnotetext{
* HITRAN does not provide any means for distinguishing pressure broadening effects due to different gases, e.g. the broadening of $\mathrm{CO}$ from water instead of air. Further literature searching or empirical measurements may be required to determine precisely any required correction.
} 
The measurements and simulations described above indicate that with appropriate corrections, the Infraran sensor can approach the 1-1.5\% measurement accuracy required for effective PMR process control.

It is also worth noting that the Infraran may be suitable for other gas sensing applications, especially those that do not need to be made in a high-temperature environment. Any gas with an infrared absorption (methane, ammonia, etc.) may be detected so long as an appropriate bandpass filter can be manufactured. Note that homonuclear diatomic molecules (hydrogen and its isotopes, nitrogen, oxygen) do not have infrared absorptions. We have shown that the sensor response may be adequately predicted using commercially available software. Measurement of trace concentrations is limited by the broad spectral bandpass, since the total signal includes nonabsorbed frequencies. However, cells with longer pathlengths can be designed to address this problem.

\subsection{ACKNOWLEDGEMENTS}

We would like to thank H.T. Sessions of SRNL for assistance with incorporation of the sensor into the PMR manifold.

\subsection{REFERENCES}

[1] R.S. Willms and K. Okuno, "Recovery of hydrogen from impurities using a palladium membrane reactor", Proc. $15^{\text {th }}$ IEEE Symp. On Fusion Eng., Hyannis, MA, Oct. 11-15, 1993, 85-90.

[2] S.A. Birdsell, R.S. Willms, P. Arzu, and A. Costello, "Effect of inlet conditions on the performance of a palladium membrane reactor", Proc. $17^{\text {th }}$ IEEE/NPS Symp. On Fusion Eng., San Diego, CA, Oct 6-10, 1997, 301-303.

[3] S.A. Birdsell and R.S. Willms, "Tritium recovery from tritiated water with a two-stage palladium membrane reactor", Fusion Eng. and Design 39-40 (1998) 1041-1048.

[4] K.D. Cleaver, "The analysis of process gases: a review”, Accred. Qual. Assur. 6 (2001) 815.

[5] P.T. Jaakkola et al., "On-line analysis of stack gas composition by a low resolution FT-IR gas analyzer”, Water, Air, and Soil Pollution 101 (1998) 79-92.

[6] J. Bak and S. Clausen, "FTIR emission spectroscopy methods and procedures for real time quantitative gas analysis in industrial environments", Meas. Sci. Technol. 13 (2002) 150156. 
[7] I. Linnerud, P. Laspersen, and T. Jaeger, "Gas monitoring in the process industry using diode laser spectroscopy”, Appl. Phys. B 67 (1998) 297-305.

[8] G. Berden, R. Peeters, and G. Meijer, "Cavity ring-down spectroscopy: Experimental schemes and applications", Int. Rev. Phys. Chem. 19 (2000) 565-607.

[9] P.A. Wilks, "In-line infrared sensors covering the mid-infrared from 2 to $14 \mu \mathrm{m}$ (5000 to $700 \mathrm{~cm}^{-1}$ )", Proc. SPIE 4577 (2002) 76-82.

[10] W. McKinney, Black Body Emission Calculator, http://infrared.als.lbl.gov/calculators/bb2001.html, 2001.

[11] David R. Lide, ed., CRC Handbook of Chemistry and Physics, Internet Version 2005, <http://www.hbcpnetbase.com>, CRC Press, Boca Raton, FL, 2005.

[12] L.S. Rothman et al., "The HITRAN molecular spectroscopic database: edition of 2000 including updates through 2001”, J. Quant. Spectrosc. Rad. Transfer 82 (2003) 5-44.

[13] W. Demtröder, Laser Spectroscopy, $3^{\text {rd }}$ printing, Springer-Verlag, Berlin, 1988. 